\title{
Acoustical Parameters of Polyvinyl Alcohol
}

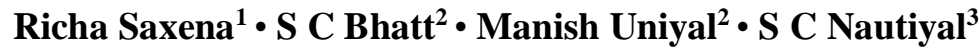

${ }^{1}$ IFTM University, Lodhipur, Rajput, Moradabad 244001, India

${ }^{2}$ Department of Physics, H N B Garhwal University Srinagar (Garhwal) 246174, India

${ }^{3}$ Department of Physics, Govt.Degree College,Raipur, Dehraun

Corresponding author Email: saxena.richa23@gmail.com

Received: 29.8.2021; Revised: 27.9.2021; Accepted: 5.11.2021

(C)Society for Himalayan Action Research and Development

\begin{abstract}
Ultrasonic investigation provides a wealth of information in understanding the intermolecular interaction of solute and solvent. An attempt has been made to measure density, viscosity and ultrasonic velocity of aqueous solution of polyvinyl alcohol of molecular weight approximately 140,000 at different temperatures $35^{\circ} \mathrm{C}, 40^{\circ} \mathrm{C}, 45^{\circ} \mathrm{C}, 50^{\circ} \mathrm{C}$, $55^{\circ} \mathrm{C}, 60^{\circ} \mathrm{C}, 65^{\circ} \mathrm{C}$ at $0.8 \%$ concentration. Ultrasonic velocity is measured using ultrasonic interferometer at $1 \mathrm{MHz}$ frequency. The acoustical parameters like, adiabatic compressibility, acoustic impedance, intermolecular free length and relaxation time have been calculated at different temperatures. These parameters were used to understand the behaviour of solute and solvent.
\end{abstract}

\section{Introduction}

Ultrasonic studies provide a wide range of information in understanding the molecular behaviour and intermolecular interaction of polymer solvent mixtures. This technique has been used extensively used to determine ionsolvent interactions in aqueous solution containing electrolytes or non electrolytes. Ultrasonic studies in polymeric solutions have drawn the attention of many researchers in the recent years (Sreenath et.al. 2012, Praharaj 2013, Nagarjun 2013, Godhani 2017). A survey of literature (Jacobson 1952, Lageman and Dunbar 1945, Kannappan 2007) indicates that acoustical parameters are useful in understanding the nature and strength of molecular interactions in the liquid mixtures and solutions. They also provide information about the process involving polymer production and their applications (Beth and Jack 2003). Polymer dissolution plays a important role in many industrial uses in a variety of application areas (Selvakumar and Bhat 2008). M. Vigneswari et al. (Vigneswari et.al. 2016) studied the molecular interactions in solutions of polyvinyl alcohol, they reported the strong solute and solvent interactions in aqueous solution of polyvinyl alcohol. Ultrasonic velocity measurements were reported for aqueous solution. They have suggested the presence of solute solvent interactions. Kavitha et al. (2012) studied the molecular interactions in aqueous solution of ternary mixture in polyvinyl alcohol. Ravichandran and Ramnathan. (2012) have 
reported, the acoustical properties and surface tension study of some potassium salts in polyacrylamide solution at $303 \mathrm{~K}$ by ultrasonic investigations and concluded the concentration, nature of the solvent and nature of the solute play an important role in determining the interactions occurring in the solutions. The acoustical parameters like adiabatic compressibility, intermolecular free-length, apparent molar compressibility, specific acoustic impedance, relative association and solvation number have been determined as they are functions of ultrasonic velocity by Ali and Nain. (1997). The present investigation is undertaken, in order to study the dependence of molecular interaction strength. The results are discussed in terms of interaction between solute and solvent.

\section{Experimental details}

In the present investigation Polyvinyl alcohol of molecular weight approximately 140,000 at different temperatures $35^{\circ} \mathrm{C}, 40^{\circ} \mathrm{C}, 45^{\circ} \mathrm{C}, 50^{\circ} \mathrm{C}$, $55^{\circ} \mathrm{C}, 60^{\circ} \mathrm{C}, 65^{\circ} \mathrm{C}$ at $0.8 \%$ concentration is used. The solutions were prepared by adding known weight of polyvinyl alcohol to fixed volume of water and stirring under reflex, until a clear solution was obtained. The polyvinyl alcohol of molecular weight approximately 140,000 at different temperatures $35^{\circ} \mathrm{C}, 40^{\circ} \mathrm{C}, 45^{\circ} \mathrm{C}, 50^{\circ} \mathrm{C}$, $55^{\circ} \mathrm{C}, 60^{\circ} \mathrm{C}, 65^{\circ} \mathrm{C}$ at $0.8 \%$ concentration is studied. Different acoustical parameters like adiabatic compressibility, acoustic impedance, intermolecular free length, and relaxation time were calculated at $35^{\circ} \mathrm{C}, 40^{\circ} \mathrm{C}, 45^{\circ} \mathrm{C}, 50^{\circ} \mathrm{C}$, $55^{\circ} \mathrm{C}, 60^{\circ} \mathrm{C}, 65^{\circ} \mathrm{C}$ temperature and at $0.8 \%$ concentration at $1 \mathrm{MHz}$ frequency. The ultrasonic velocity was measured by using variable path ultrasonic interferometer with accuracy of $\pm 0.4 \mathrm{~m} / \mathrm{s}$ at $35^{\circ} \mathrm{C}$. By circulating water from the thermostatically controlled $\left( \pm 0.1^{\circ} \mathrm{C}\right)$ water bath, the temperature of the solution has been kept constant. The densities of PVA at different temperature were also measured. The accuracy in density measurements was about $0.5 \mathrm{~kg} / \mathrm{m}^{3}$. The viscosity of the mixtures was determined by using Ostwald's viscometer at constant temperature also. The accuracy in the viscosity measurements is within $\pm 0.5 \%$. These parameters are calculated by using standard relations (Bhandakkar and Rode 2012, Saxena and Bhatt (2010,2017, Saxena et al 2020).

\section{Result and Discussion}

The experimentally obtained valued of density, viscosity and ultrasonic velocity at $35^{\circ} \mathrm{C}, 40^{\circ} \mathrm{C}$, $45^{\circ} \mathrm{C}, 50^{\circ} \mathrm{C}, 55^{\circ} \mathrm{C}, 60^{\circ} \mathrm{C}, 65^{\circ} \mathrm{C}$ temperature and at $0.8 \%$ concentration at $1 \mathrm{MHz}$ frequency are used to calculate different acoustical parameters adiabatic compressibility, acoustic impedance, intermolecular free length and relaxation time for aqueous solution of Polyvinyl alcohol, that have been presented in Table 1, 2, 3, 4, 5, 6 and 7 respectively.

Density is a measure of solute-solvent interaction. Table-1 and Fig 1 represent the variation of density with temperature at $0.8 \%$ 
concentration for polyvinyl alcohol. It is found that with increase in temperature, density decreases. Present results are in good agreement with earlier reported data (Sridevi 2004, Kannapan and Shanti 2005, Kerrboub et.al 2005). Viscosity decreases with increase in temperature of polyvinyl alcohol (Table 2, Figure 2). It may be due to decrease in the cohesive forces. Results are in similar trend with the earlier researchers (Esquivel et al 1993). It is observed that with the increase of temperature, ultrasonic velocity decreases in polyvinyl alcohol solution. (Table 3, Figure 3). It may be

Table: 1- Density $\left(\mathrm{x} 10^{3} \mathrm{~kg} / \mathrm{m}^{3}\right)$ of Polyvinyl alcohol (PVA) with temperature at $0.8 \%$ concentration at $1 \mathrm{MHz}$ frequency-

\begin{tabular}{cc}
$\begin{array}{c}\text { TEMPERATURE } \\
\left({ }^{\circ} \mathbf{C}\right)\end{array}$ & DENSITY \\
\hline 35 & 0.983 \\
40 & 0.981 \\
45 & 0.979 \\
50 & 0.977 \\
55 & 0.972 \\
60 & 0.964 \\
65 & 0.956
\end{tabular}

Table: 2-Viscosity $\left(\mathrm{x} 10^{-1} \mathrm{~Pa} . \mathrm{sec}\right)$ of Polyvinyl alcohol (PVA) with temperature at $0.8 \%$ concentration at $1 \mathrm{MHz}$ frequency-

TEMPERATURE VISCOSITY

$\left({ }^{\circ} \mathrm{C}\right)$

$\begin{array}{cc}35 & 0.086 \\ 40 & 0.084 \\ 45 & 0.081 \\ 50 & 0.0781 \\ 55 & 0.069 \\ 60 & 0.059 \\ 65 & 0.056\end{array}$

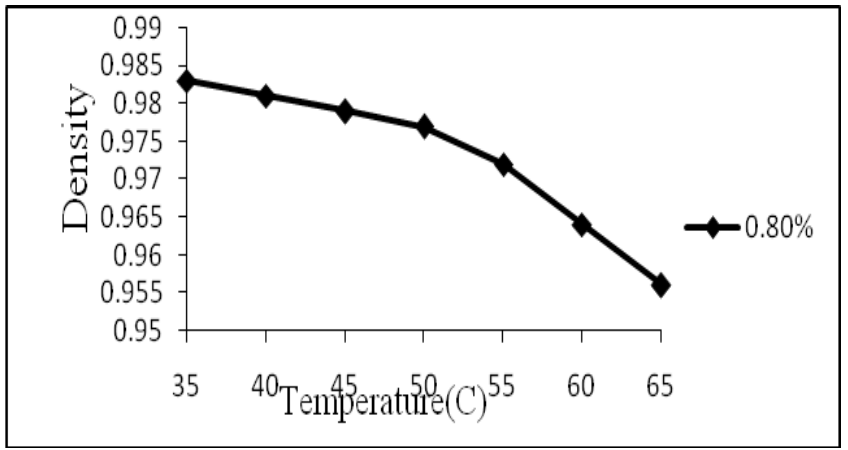

Fig.-1: Variation of density with temperature at $0.8 \%$ concentration

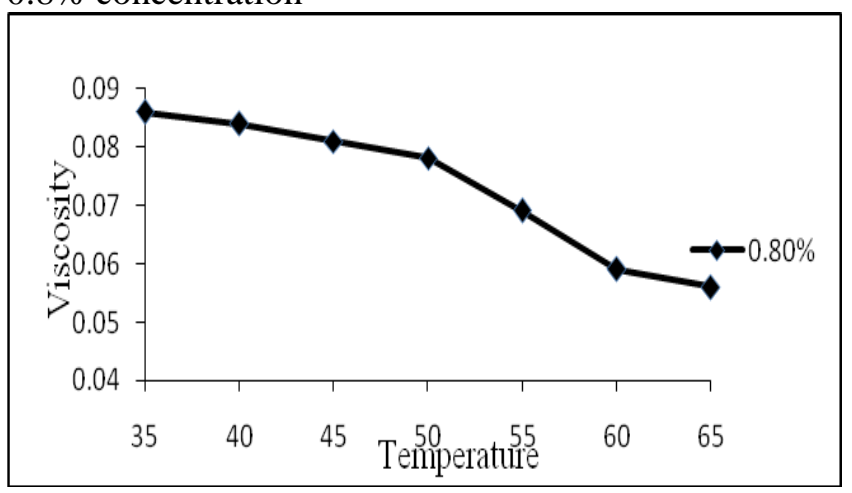

Fig.-2: Variation of viscosity with temperature at $0.8 \%$ concentration

due to increase in temperature, available thermal energy facilitates the breaking of bonds between the associated molecules. The increase in thermal energy weakens the molecular forces which decreases the ultrasonic velocity. The variation of ultrasonic velocity in solution depends on intermolecular free length on mixing. On the basis of a model, for sound propogation proposed by Eyring and Kincaid (1938), ultrasonic velocity should decrease, if the intermolecular free length increase and viceversa. This is observed in the present investigation. This increase or decrease in value of ultrasonic velocity with composition indicates interactions between contributing molecules. This behaviour is in good agreement with the 
behavior reported by earlier reported data(Baba and Subha, 2002). Table 4 and Fig. 4 reports the variation of adiabatic compressibility with temperature. It is clearly seen that adiabatic compressibility increases with temperature of polyvinyl alcohol in solution. This indicates solute solvent interaction. Similar results are reported by other researchers (Syal et al 2005). Variation of acoustic impedance with temperature is shown in (Table 5 and Fig.5) it is seen that it decreases with increase in temperature. These results also support the conclusions drawn from deviation in ultrasonic velocity. It is observed from Table 6 and Fig. 6 that Intermolecular free length increases with increase in temperature. Variation of relaxation time with temperature at $0.8 \%$ concentration is shown in Table 7 and Fig 7. It decreases with increase in temperature. This trend is quite normal as the variation in these parameters is the cumulative effect of the variations in density, viscosity and ultrasonic velocity of the solutions under the given condition. This may be due to as per the kinetic theory of fluid.

Table: 3-Ultransonic velocity $(\mathrm{m} / \mathrm{s})$ of polyvinyl alcohol (PVA) with temperature at $0.8 \%$ concentration at $1 \mathrm{MHz}$ frequency

TEMPERATURE ULTRASONIC

\begin{tabular}{cc}
$\left({ }^{\circ} \mathbf{C}\right)$ & VELOCITY \\
\hline 35 & 1503.2 \\
40 & 1500.1 \\
45 & 1498.8 \\
50 & 1488.7 \\
55 & 1473.4 \\
60 & 1470.6 \\
65 & 1467.7
\end{tabular}

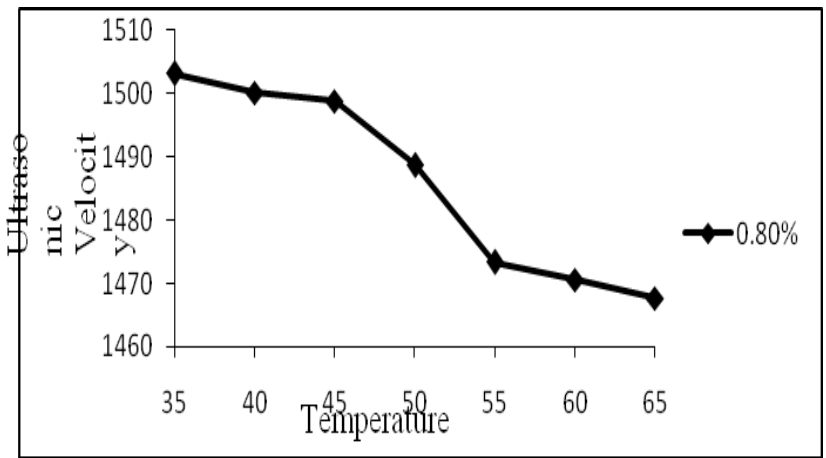

Fig.-3: Variation of ultrasonic velocity with temperature at $0.8 \%$ Concentration

Table: 4- Adiabatic compressibility $\left(\times 10^{-10} \mathrm{~kg}^{-}\right.$ ${ }^{1} \mathrm{~ms}^{2}$ ) of Polyvinyl alcohol (PVA) with temperature at $0.8 \%$ concentration $1 \mathrm{MHz}$ for polyethylene glycol (PEG)-

\begin{tabular}{c|c}
$\begin{array}{c}\text { TEMPERATURE } \\
\left({ }^{\circ} \mathbf{C}\right)\end{array}$ & $\begin{array}{c}\text { ADIABATIC } \\
\text { COMPRESSIBILITY }\end{array}$ \\
\hline $\mathbf{3 5}$ & 4.502 \\
$\mathbf{4 0}$ & 4.53 \\
$\mathbf{4 5}$ & 4.547 \\
$\mathbf{5 0}$ & 4.618 \\
$\mathbf{5 5}$ & 4.739 \\
$\mathbf{6 0}$ & 4.747 \\
$\mathbf{6 5}$ & 4.856 \\
\hline
\end{tabular}

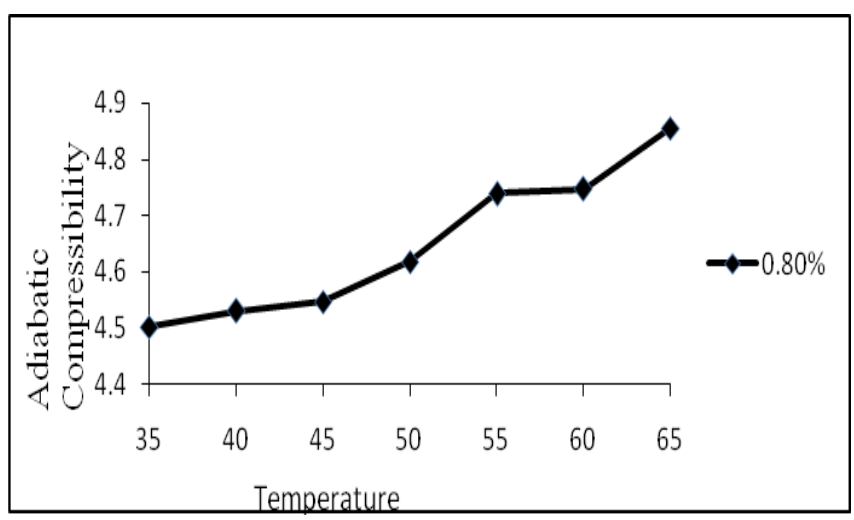

Fig.-4: variation of adiabatic compressibility with temperature at $0.8 \%$ Concentration 
Table: 5- Acoustic impedance $\left(\mathrm{x} 10^{3} \mathrm{kgm}^{2} \mathrm{~s}^{-1}\right)$ of Polyvinyl alcohol (PVA) with temperature at $0.8 \%$ concentration at $1 \mathrm{MHz}-$

\begin{tabular}{cc|}
$\begin{array}{c}\text { TEMPERATURE } \\
\left({ }^{\circ} \mathbf{C}\right)\end{array}$ & $\begin{array}{c}\text { ACOUSTIC } \\
\text { IMPEDANCE }\end{array}$ \\
\hline 35 & 1477.6 \\
40 & 1471.6 \\
45 & 1467.3 \\
50 & 1454.5 \\
55 & 1432.1 \\
60 & 1417.7 \\
65 & 1403.1 \\
\hline
\end{tabular}

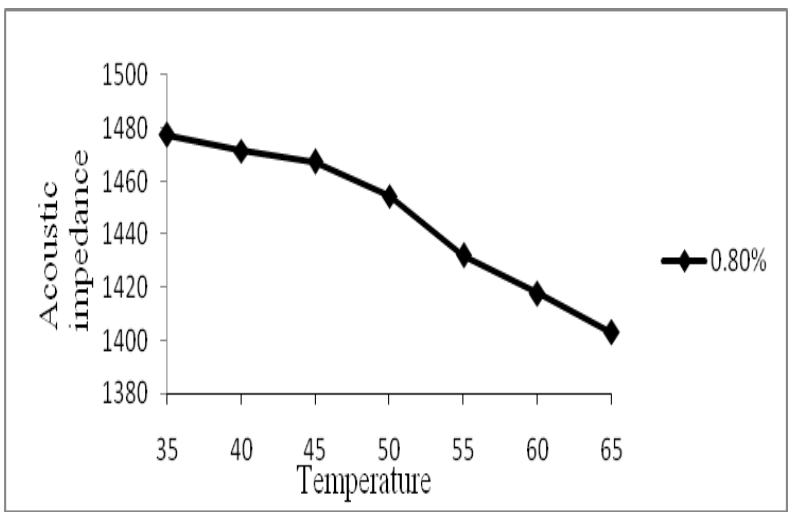

Fig.-5: Variation of Acoustic Impedance with temperature at $0.8 \%$ Concentration

Table: 6- Intermolecular Free Length $\left(\times 10^{-13} \mathrm{~m}\right)$ of Polyvinyl alcohol (PVA) with temperature at $0.8 \%$ concentration at $1 \mathrm{MHz}-$

\section{TEMPERATURE INTERMOLECULAR} $\left({ }^{\circ} \mathrm{C}\right)$

\section{FREE LENGTH}

\begin{tabular}{|ll}
\hline 35 & 2.872 \\
40 & 2.881 \\
45 & 2.886 \\
50 & 2.909 \\
55 & 2.946 \\
60 & 2.964 \\
65 & 2.983 \\
\hline
\end{tabular}

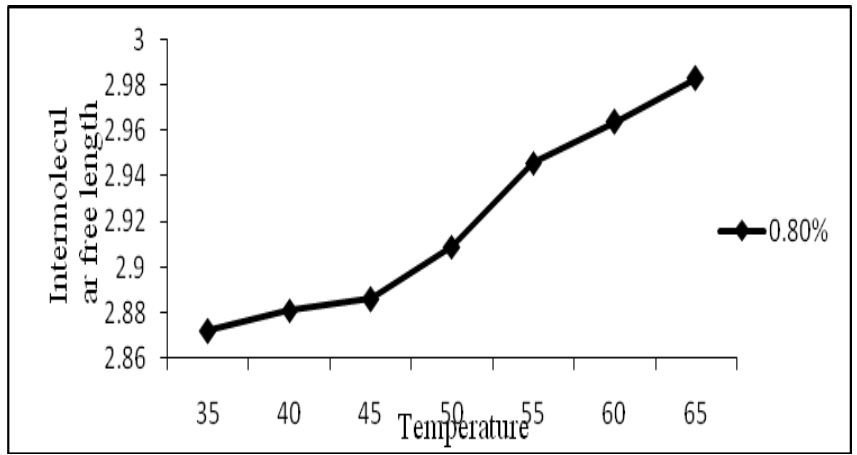

Fig.-6: Variation of intermolecular free Length with temperature at $0.8 \%$ Concentration

Table: 7 - Relaxation time (x10-12 $\mathrm{s}$ ) of polyvinyl alcohol with temperature at $0.8 \%$ concentration at $1 \mathrm{MHz}$ frequency

\begin{tabular}{cc}
$\begin{array}{c}\text { TEMPERATURE } \\
\left({ }^{\circ} \mathbf{C}\right)\end{array}$ & $\begin{array}{c}\text { RELAXATION } \\
\text { TIME }\end{array}$ \\
\hline 35 & 1.709 \\
40 & 1.255 \\
45 & 1.336 \\
50 & 0.992 \\
55 & 0.902 \\
60 & 0.764 \\
65 & 0.759 \\
\hline
\end{tabular}

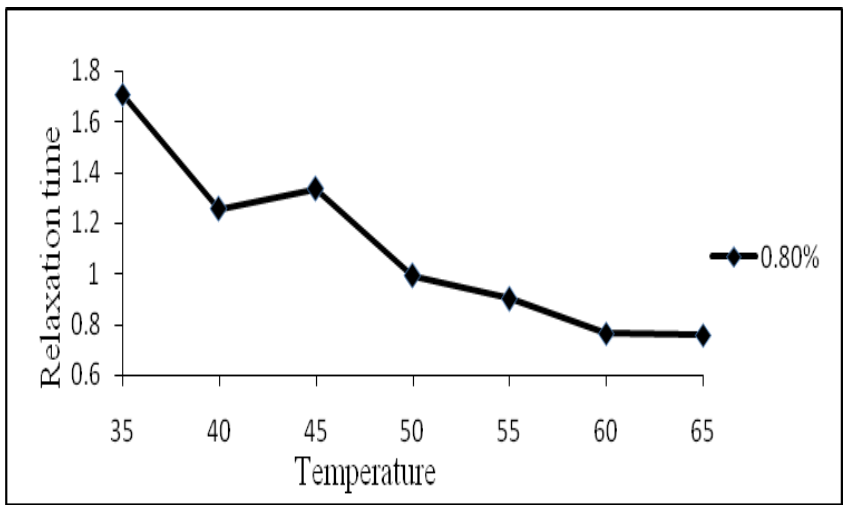

Fig.-7: Variation of relaxation time with temperature at $0.8 \%$ Concentration

\section{Conclusion}

The ultrasonic velocity measurement technique is a effective and powerful tool to investigate 
properties of polymer solution and nature of polymer chain in ultrasonic field. Densities, viscosity, ultrasonic velocities of the aqueous solution of Polyvinyl alcohol have been experimentally determined at $35^{\circ} \mathrm{C}, 40^{\circ} \mathrm{C}, 45^{\circ} \mathrm{C}, 50^{\circ} \mathrm{C}, 55^{\circ} \mathrm{C}, 60^{\circ} \mathrm{C}, 65^{\circ} \mathrm{C}$. The values of density and viscosity decrease with increase temperature. This may be due to decrease in an inner molecular forces and increasing thermal energy. The increase of the temperature increases the thermal energy that in turn decrease the ultrasonic velocity. Free length shows molecular interaction between surfaces of molecules so it increase the molecular free energy. The variation in the acoustical parameters suggests that there are strong solute solvent interactions.

\section{References}

Ali A, Nain AK (1997) Indian Journal of pure and applied Ultrasonics, Ultrasonic studies of formamide+ 1, 2-ethanediol and sodium iodide+ formamide+ 1, 2-ethanediol mixtures at $298.15 \mathrm{~K}, 19: 41$

Baba N Surendra, Subha MCS (2002) J. Indian Chem. Soc., 79: 505.

Beth AMC and Jack LK (2003) Prog. Polymer Sci, 28: 1223.

Bhandakkar VD and Rode Shweta S (2012) Acoustical studies on molecular interactions in binary liquid mixtures at
303K, Advances in Applied Science Research, 3: 3223-3229.

Erything HJ and Kincaid JF (1938) Free volumes and free angle ratios of molecules in liquids, J. Chem. Phys. (USA) 6: 620629.

Esquivel R,Tan B, Abdelraziq I, Yunand SS, Stump FB, (1993) Absorption and velocity of ultrasound in binary solutions of polyethylene glycol and water, J. Acoustical Soc. Am., 93: 819.

Godhani DR, Dobariya PB, Sanghani AM and Mehta JP (2017) Thermodynamic properties of binary mixtures of 1,3,4oxadiazole derivative with chloroform, N,N-dimethyl formamide at 303, 308 and $313 \mathrm{~K}$ and atmospheric pressure, Arabian J of Chemistry, 17:S422-S430.

Jacobson B (1952) Ultrasonic Velocity in Liquids and Liquid Mixtures, J. Chem. Phys., 20, 927.

Kannapan V, Shanti R Jaya (2005) Ultrasonic study of induced dipole-dipole interactions in binary liquid mixtures, Indian J Pure \& Applied Physics, 43:750.

Kannappan V, Vinayagam S Chidambaram (2007) Ultrasonic investigation of ionsolvent interactions in aqueous and nonaqueous solutions of transition and inner transition metal ions, Indian J of Pure App Phy, 45: 143-150. 
Kavitha R, Jayakumar S, Uma R (2012) Ultrasonic Study of Molecular Association of Ternary Mixtures in Polyvinyl Alcohol, Stearates and Ethylene Glycol IOSR Journal of Applied Chemistry (IOSR-JAC) 3: $36-43$.

Kerrboub Wahiba, A Atik Zadjia, (2010) J Chem Thermodynamics, 42:1330.

Lageman RJ, Dunbar WS (1945) Relationship between the velocity of sound and other physical properties of liquid, J. Phys. Chem.,49 428-436.

Nagarjun B, Sharma AV, Rama Rao GV and Rambabu C (2013) Thermodynamic and Acoustic Study on Molecular Interactions in Certain Binary Liquid Systems Involving Ethyl Benzoate, $\mathbf{J}$ of Thermodynamics, 2013, 1-9.

Praharaj MK, Sathapathy A, Mishra P and Mishra S (2013) Ultrasonic studies of ternary liquid mixtures of N-Ndimethylformamide, nitrobenzene, and cyclohexane at different frequencies at 318 K J of theoretical and Applied Physics,7:16.

Ravichandran S, Ramanathan K(2012) Acoustical Properties and Surface Tension study of some Potassium salts in Polyacrylamide solution at 303K, Res. J. Chem. Sci., 2 49-54.
Saxena Richa and Bhatt SC (2010) International $\mathrm{J}$ of Chemistry, 2: 164.

Saxena Richa and Bhatt SC (2017) Rasayan J of Chemistry,10:1340-1347.

Saxena Richa, Bhatt SC, Uniyal Manish and Nautiyal SC (2020) Applied Innovative Research, Vol. 2, March, pp. 36-38.

Selvakumar M \& Bhat Krishna (2008) Indian Journal of Pure and applied Physics, 46: 12-18.

Sreenath K, Kondaiah M, Sravana Kumar D and Rao Krishna (2012) Excess Acoustical and Volumetric Properties and Theoretical Estimation of Ultrasonic Velocities in Binary LiquidMixtures of 2-Chloroaniline with Acrylic Esters at $308.15 \mathrm{~K}$, Journal of Solution Chemistry, 41: 1088-1102.

Sridevi U, Samatha K \& Sharma Viswanatha A (2004) Excess thermodynamic properties in binary liquids, J. Pure \& Appl. Ultrasonics, 26:1-11.

Syal VK, Chauhan Anita and Chauhan Suvarcha (2005) Ultrasonic velocity, viscosity and density studies of poly (ethylene glycols)(PEG - 8,000, PEG - 20,000) in acetonitrile (AN) and water $(\mathrm{H} 2 \mathrm{O})$ mixtures at $250 \mathrm{C} \mathrm{J}$. of pure and applied Ultrasonics, 27:61-69.

Vigneswari M, Saravanakumar SS, Sureshbabu VN, Sankarraja S(2016) International Journal of Advanced Chemistry, 4:15-21. 